\title{
The effects of mobile text messages on raising knowledge of men with type 2 diabetes, Isfahan, 2015: an educational experimental study
}

\author{
Fataneh Goodarzi ${ }^{1}$, Shakiba Zahed ${ }^{2}$, Akbar Hassanzadeh $^{3}$, Mahmood Nasr Esfahani $^{4}$, Mojgan Nourian ${ }^{5}$, \\ Fereshteh Zamani-Alavijeh ${ }^{6}$
}

${ }^{1}$ M.Sc., Student Research Committee, School of Health, Isfahan University of Medical Sciences, Isfahan, Iran

${ }^{2} \mathrm{Ph}$.D. Candidate, Department of Health Education and Promotion, School of Heath, Isfahan University of Medical Sciences, Isfahan, Iran

${ }^{3}$ Lecturer, Department of Biostatistics and Epidemiology, School of Health, Isfahan University of Medical Sciences, Isfahan, Iran

${ }^{4}$ Manager, Department of Patient Health Education, Alzahra University Hospital, Isfahan University of Medical Science, Isfahan, Iran

${ }^{5}$ Assistant Professor, Department of Community Nutrition and Food Science Faculty, Isfahan University of Medical Sciences, Isfahan, Iran

${ }^{6}$ Associate Professor, Department of Health Education and Promotion, School of Health, Isfahan University of Medical Sciences, Isfahan, Iran

Type of article: Original

\begin{abstract}
Background: Diabetes is one of the most common metabolic disorders which are rapidly increasing. Distance training is a cost-effective, easy and accessible way in which time and place dimensions of communication are removed.

Objective: To determine the effects of mobile text messages on raising knowledge of men with type 2 diabetes. Methods: This educational experiment recruited 76 people selected by convenient sampling from a population of male patients with type 2 diabetes presenting to Sedigheh Tahereh Research Center in Isfahan, Iran, in 2015. They were randomly assigned into intervention and control groups. Data were collected with a questionnaire of demographic characteristics and questions pertaining to the variable of knowledge, through interview. The intervention group received training and follow-up through cell phones and text messages for 12 weeks. Data were analyzed in IBM-SPSS version 20 using Mann-Whitney test, Chi-square, Independent-samples t-test and paired-samples t-test.

Results: Findings suggested that patients' knowledge in both groups significantly increased after the training $(p<0.001)$. However, this rise in the intervention group was significantly higher than that of the control group $(\mathrm{p}<0.001)$.

Conclusion: The results indicated that designing and implementing educational programs based on text messages and cell phones can improve knowledge in diabetics.
\end{abstract}

Keywords: Type 2 diabetes, Text messages, Knowledge

\section{Introduction}

Diabetes is a non-communicable metabolic disorder which is growing across the world, and has a high annual mortality rate (1-4). The prevalence of diabetes was reported as $7.3 \%$ in people over 30 years old (5). Diabetics live 7 to 10 years less than otherwise healthy people as well as suffer from diabetes complications (6-8). In order to

\section{Corresponding author:}

Associate Professor Dr. Fereshteh Zamani-Alavijeh, School of Health, Isfahan University of Medical Sciences, Isfahan, Iran.

Tel:+98.3137923292, Fax:+98.3136682509, Email: fe.zamani@gmail.com, and f_zamani@hlth.mui.ac.ir

Received: June 07, 2017, Accepted: March 12, 2018, Published: August 2018

iThenticate screening: February 17, 2018, English editing: May 31, 2018, Quality control: May 31, 2018

This article has been reviewed / commented by three experts

Funding / research project approval: 394830

Ethics approval: IR.MUI.REC.1394.30.830

(C) 2018 The Authors. This is an open access article under the terms of the Creative Commons Attribution-NonCommercialNoDerivs License, which permits use and distribution in any medium, provided the original work is properly cited, the use is non-commercial and no modifications or adaptations are made. 
reduce diabetes complications (e.g. visual, renal side effects and amputations from diabetes) patients should be made aware of how to prevent, treat and manage the disease (8). Given the growing prevalence of diabetes and the significance of continuous follow-ups, it is necessary to find a practical method for patients' education (9). Studies show that self-care behavior is not sufficient among diabetic patients $(10,11)$. For this reason, design and evaluation of the appropriate educational interventions is necessary for them to learn healthy behaviors. But many of them, especially men, do not participate in educational programs of hospitals and other centers due to long distances, time constraints and work. Furthermore, holding in-person training sessions are labor-intensive, costly and timeconsuming $(9,12-15)$. Despite all these obstacles and challenges, the patients' training should be continuous so that patients' knowledge is continuously improved (9). Thus, using modern technologies, such as mobile phone, for patient education may be one of the appropriate responses to these challenges of today's society (11). Diabetes is a complex disease. Therefore, new technologies can save time and money, help control diabetics continuously, improve their access to medical care and follow them up continuously (16-18). Cell phones are among communication devices that are increasingly used for distance training in people's daily life (10, 19). Another feature of this technology is its availability in all places and all times $(10,17,19)$. In terms of time and place, cell phones may facilitate patients' learning at home, at work and on trips (10). Thus, given the needs of male diabetics to an accessible learning system $(10,20)$, and the few studies in this field in Iran, the current study aimed to determine the effects of distance training by cell phones and text messages on raising knowledge of men with type 2 diabetes, in Isfahan.

\section{Material and Methods}

\subsection{Research design and sample size}

This educational experiment was conducted on a statistical population of male patients with type 2 diabetes presenting to one of the research centers in Isfahan, from May to September 2015. Seventy-six people $(\mathrm{d}=0.7 \mathrm{~s}$, $\beta=0.20, \alpha=0.5$, and considering $15 \%$ probability of sample loss) were selected by convenient sampling and randomly divided into intervention and control groups of 38 people each.

\subsection{Selection criteria}

The inclusion criteria were as follows: more than six months had passed since the diagnosis of diabetes, resident of Isfahan, and reading and writing ability. The only exclusion criterion was the unwillingness to continue participating in the study. The study flowchart is illustrated in Figure 1.

\subsection{Instrument, validity and reliability}

The instrument used in the research was a researcher-made questionnaire. The questionnaire consisted of two parts. The first part comprised demographic data with 16 questions on age, education, occupation, and duration of diabetes, while the second part included 17 questions on knowledge. Each question was scored 3 for the right answer, 2 for 'I do not know', and 1 for the wrong answer. The range of knowledge score was from 17 to 51 . The validity of the questionnaires was measured using qualitative content and face validities. The questionnaire was given to 30 diabetic men to confirm the face validity. Their oral comments were obtained and administered to correct the questionnaire. Cronbach's alpha was calculated as 0.82 and confirmed as a desirable reliability.

\subsection{Intervention and data collection}

The questionnaires were completed through interviews with patients. After the pre-test, patients in the intervention group took part in an educational and briefing session at the center, and their landline and cell phone numbers were obtained. The patients' cell phones were checked to see if they had Persian menu, and the questions and problems were answered. Using literature review (21-26) and an experts panel, an item pool was developed. Validation of educational messages was conducted based on the sources and related articles $(21,27)$. In order to validate the messages, the experts panel of 10 specialists, 3 in health education, 2 in nutrition sciences, 1 in nursing, 2 in statistics and 2 epidemiologists were asked to submit their suggestions, and apply and review the contents of the message and say whether the messages are correct. Then the messages were corrected based on their comments. Messages were sent twice a week, every 3 months, and each time, with an educational content. The text of each message was no longer than 160 characters. Each message was coded, and once the message was delivered to the patients, it was marked on a checklist. In addition to receiving educational messages, the intervention group received the routine training and advice of that center. After the intervention, the post-test was conducted.

\subsection{Statistical analysis}

Data were analyzed using descriptive statistics, Mann-Whitney, Chi-square, paired-samples t-test, and Independentsamples t-test, by IBM@ SPSS $\odot$ Statistics version 21 (IBM@ Corp., Armonk, NY, USA). 


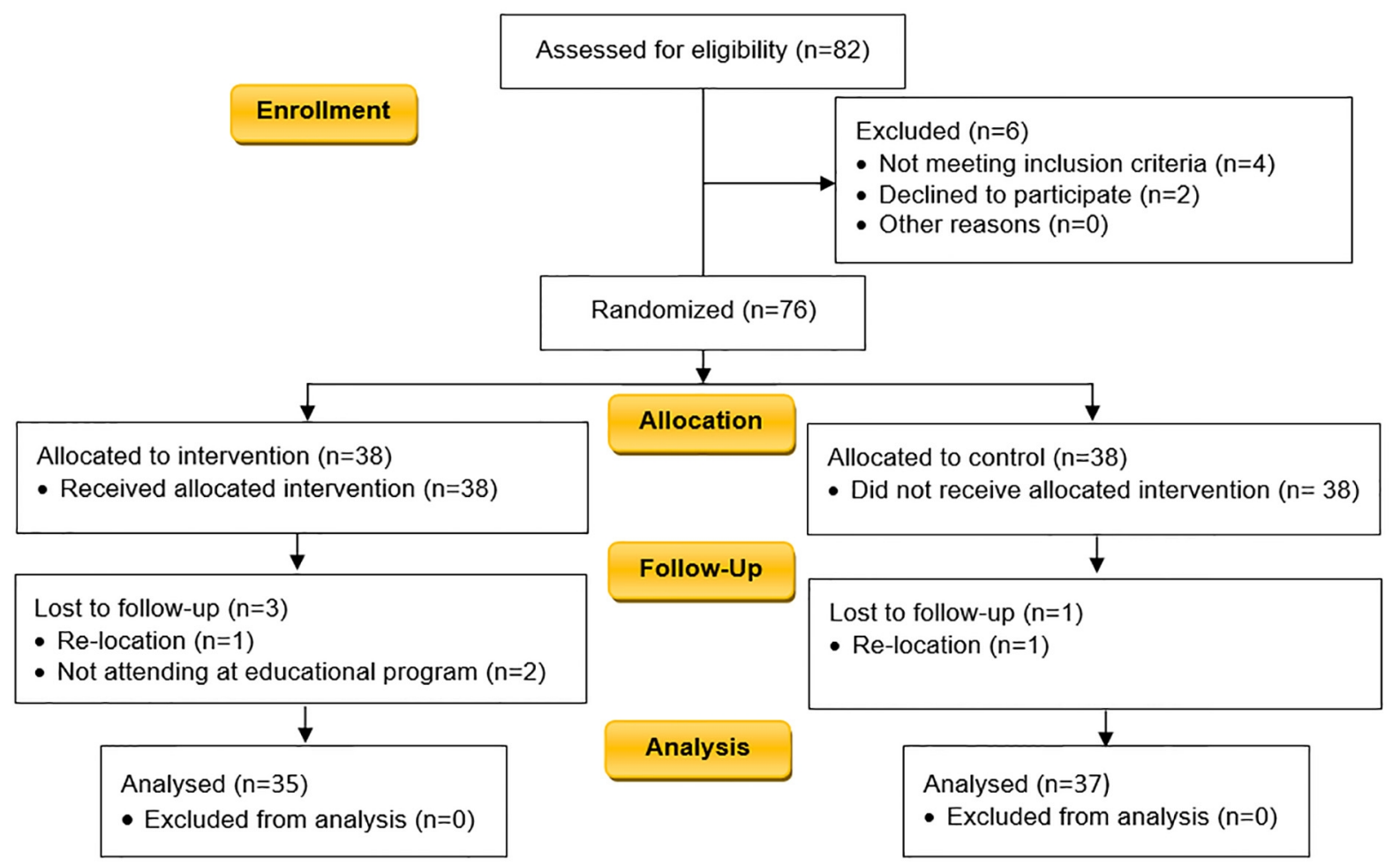

Figure 1. Study flowchart

\subsection{Ethics approval and consent to participate}

All participants were informed about the study and confidentiality protocols. Informed consent was obtained from all the participants; the study was approved by the ethics committee of Isfahan University of Medical Sciences (Ref. no.: IR.MUI.REC.1394.30.830).

\section{Results}

Overall, 72 participants (37 people in the control group and 35 people in the intervention group), who were over 30 years old, completed the study. The mean age of the intervention and control groups were $57.68 \pm 8.82$ years and $57.27 \pm 7.89$ years, respectively. There was no significant difference between the age of the two groups $(\mathrm{p}=0.83)$. The mean weight of the intervention group was $81.2 \mathrm{~kg}$, and of the control group was $80 \mathrm{~kg}$, showing no significant difference between the two groups $(\mathrm{p}=0.73)$. The two groups also matched in terms of the family size and duration of diagnosis (Table 1).

Table 1. Comparison of demographic and disease characteristics in patients with type 2 diabetes in study groups

\begin{tabular}{|c|c|c|c|c|}
\hline \multicolumn{2}{|l|}{ Variables } & Intervention & Control & p-value \\
\hline \multicolumn{2}{|l|}{ Age (year) } & $57.68 \pm 8.82$ & $57.27 \pm 7.89$ & 0.83 \\
\hline \multicolumn{2}{|l|}{ Weight $(\mathrm{kg})$} & $81.25 \pm 14.98$ & $80 \pm 15.75$ & 0.73 \\
\hline \multicolumn{2}{|l|}{ Family size } & $4.71 \pm 1.94$ & $5.33 \pm 1.85$ & 0.17 \\
\hline Duration of diabetes & Month & $12.51 \pm 8.96$ & $9.24 \pm 7.46$ & 0.09 \\
\hline \multirow[t]{5}{*}{ Education } & Ability to read and write & $1(2.9)$ & $2(5.4)$ & \multirow[t]{4}{*}{0.38} \\
\hline & Elementary school & $7(20)$ & $7(18.9)$ & \\
\hline & Junior high school & $5(14.3)$ & $9(24.3)$ & \\
\hline & High school diploma & $14(40)$ & $9(24.3)$ & \\
\hline & Higher education & $8(22.9)$ & $10(27)$ & \\
\hline \multirow[t]{3}{*}{ Marital status } & Single & $0(0)$ & $1(2.7)$ & \multirow[t]{3}{*}{0.49} \\
\hline & Married & $34(97.1)$ & $35(94.6)$ & \\
\hline & Others & $1(2.9)$ & $1(2.7)$ & \\
\hline \multirow[t]{3}{*}{ Economic level } & Low & $14(40)$ & 12 & \multirow[t]{3}{*}{0.779} \\
\hline & Moderate & $18(51.4)$ & 22 & \\
\hline & High & $3(8.6)$ & 3 & \\
\hline
\end{tabular}


Table 2 shows that knowledge about diabetes was not significantly different between the intervention group (50.25 \pm 23.37$)$ and the control group $(48.97 \pm 22.01)$ before the training $(\mathrm{p}=0.81)$. Patients' knowledge after the training compared to the past, saw a rise in both intervention and control groups; however, this rise was significantly higher in the intervention group than that of the control group $(\mathrm{p}<0.001)$ (Table 2). The increase in the score of knowledge in both groups was compared. The difference of knowledge score, before and after the training, was $47.9 \pm 19.4$ in the intervention group and $12.71 \pm 4.44$ in the control group. Independent-samples t-test results indicated that the change made in the intervention group was significantly higher than that of the control group.

Table 2. Comparison of the mean score of knowledge in intervention and control groups before and after the intervention

\begin{tabular}{|c|c|c|c|}
\hline Knowledge & Intervention & Control & p-value \\
\hline Before intervention & $50.25(23.37)$ & $48.97(22.01)$ & 0.81 \\
\hline After intervention & $98.15(3.97)$ & $61.68(17.57)$ & 0.000 \\
\hline$p$-value ${ }^{2}$ & 0.000 & 0.003 & \\
\hline
\end{tabular}

1: Independent-samples t-test; 2: paired-samples t-test

\section{Discussion}

The current study investigated the effects of cell phone text messages on improving diabetics' knowledge. Our results suggested that the knowledge score before the intervention was not significantly different between the intervention and control groups. However, after the intervention, the knowledge score increased in both groups. Hence, it can be concluded that the current educational interventions at the Diabetes Center, including holding educational classes, giving out educational pamphlets to patients, training during filing, care and control services for patients were effective in improving the control group's knowledge. On the one hand, the mean knowledge score in the intervention group was significantly higher than that of the control group. Although increased knowledge of the study group seemed normal, and many similar studies with educational interventions mention this point $(22,23)$, the level of improvement and increase in knowledge was considerable in the intervention group. If nutrition, sports activity and medications are considered to be the three main elements in treating diabetes, the fourth element must undoubtedly be training (20). Thus, educational content and the application of an educational method appropriate to the target group is a major factor in changing the knowledge of the study population (24). The study results suggested that the increase in knowledge of the intervention group was significantly higher than that of the control group, therefore, new technologies can have stronger effects compared to conventional interventions $(10,20,25)$. It is worth noting that communication devices such as cell phones are needed for training and increasing patients' knowledge $(10,20)$.

Parizad et al. showed that patients' awareness of self-care behaviors in different dimensions increases significantly after follow-up and distance education via mobile phone and Short Message Service (SMS) (20). Their findings were in line with the results of the present study on awareness increase, and the use of similar modern educational methods. Another similar study showed that telephone follow up is an effective way to increase the awareness of patients in improving the different dimensions of self-care behaviors (26). The results of the research mentioned in this study that in this case, distance education is more convenient and requires less manpower, and this method of follow-up is very convenient for people with type 2 diabetes who are often middle-aged and old. In this regard, Gharaati et al., consistent with the present study, showed that mobile phone education resulted in significant positive changes in the knowledge of individuals (28). On the other hand, Absavaran et al. showed that education through the cell phone, also increases awareness in promoting health behaviors (29). Baker et al. Showed that patients' knowledge about self-care behaviors increased after telephone intervention (30). Also, studies by Goodarzi et al. (31) and Baghiani Moghadam et al. (32) showed that educational intervention via telephone and short message service significantly promotes the awareness of patients with type 2 diabetes. The results of some studies that compared the traditional methods (face to face) and distance education showed that distance learning is easier for patients, more cost-effective and more educational. Therefore, it may be the most appropriate method to help patients to raise awareness and promote self-care behaviors (33). Fatehi et al. reported that education for diabetic patients through short message service has increased awareness of patients (34). Therefore, findings of the research mentioned with the results of this study are aimed at increasing awareness and then improving self-care behaviors and improving the quality of life of patients.

\section{Limitation}

The statistical population consisted of type 2 diabetics in the city of Isfahan which limits the generalizability of the result. Thus, future studies are recommended with larger sample sizes. Furthermore, no reference was made to the 
effects of the interventions on self-care attitudes and behaviors, and it is essential to measure the effects of knowledge on self-care attitudes and behaviors.

\section{Conclusions}

Our study results, in line with other studies in and out of Iran, suggest that cell phones can help design and implement educational interventions and sometimes achieve even better results. Thus, the salient point in this study is to use cell phones for distance training. Today, training and self-care are emphasized more than treatment. Hence, educational interventions are introduced to increase patients' knowledge about prevention and management of diseases.

\section{Acknowledgments:}

This study was part of a registered M.Sc. thesis (Ref. no. 394830). Financial support was received from Isfahan University of Medical Sciences. The authors express their gratitude to the Isfahan University of Medical Sciences for its financial support, and all authorities and patients who assisted us.

\section{Conflict of Interest:}

There is no conflict of interest to be declared.

\section{Authors' contributions:}

All authors contributed to this project and article equally. All authors read and approved the final manuscript.

\section{References:}

1) Organization WH. Definition and diagnosis of diabetes mellitus and intermediate hyperglycaemia: report of WH. 2006.

2) Piri A. Effects of education based on health belief model on dietary adherence in diabetic patients. Journal of Diabetes and Metabolic Disorders. 2010; 9(15): 1-6.

3) Guariguata L, Whiting D, Hambleton I, Beagley J, Linnenkamp U, Shaw J. Global estimates of diabetes prevalence for 2013 and projections for 2035. Diabetes research and clinical practice. 2014; 103(2): 13749. doi: 10.1016/j.diabres.2013.11.002. PMID: 24630390.

4) World Health Organization. Global report on diabetes. 2016. Available from: http://www.who.int/diabetes/country-profiles/en/.

5) Tol A, Tavassoli E, Sharifirad G, Shojaezadeh D, Azadbakht L. The relationship between socioeconomic factors and their effects on patients with type 2 diabetes. 2011; 7(1): 128-47.

6) Delavari A, Mahdaviehezaveh A, Norouzinejad A, Yarahmadi S. Diabetes control and prophylaxes civil program. Tehran, Iran: Ceda Publication; 2004.

7) Skyler JS. Diabetic complications: the importance of glucose control. Endocrinology and Metabolism Clinics. 1996; 25(2): 243-54. doi: 10.1016/S0889-8529(05)70323-6.

8) McDuffie RH, Struck L, Burshell A. Empowerment for diabetes management: integrating true selfmanagement into the medical treatment and management of diabetes mellitus. Ochsner J. 2001; 3(3): 14957. PMID: 22754392, PMCID: PMC3385781.

9) Peck A. Changing the face of standard nursing practice through telehealth and telenursing. Nursing administration quarterly. 2005; 29(4): 339-43. doi: 10.1097/00006216-200510000-00008. PMID: 16260998.

10) Lee RG, Hsiao CC, Chen KC, Liu MH. An intelligent diabetes mobile care system with alert mechanism. Biomedical Engineering: Applications, Basis and Communications. 2005; 17(04): 186-92. doi: $10.4015 / \mathrm{S} 1016237205000299$.

11) Lee WW, Owens DL. Multimedia-based instructional design: computer-based training, web-based training, distance broadcast training, performance-based solutions: John Wiley \& Sons; 2004.

12) Goodarzi M, Ebrahimzadeh I. Impact of Distance Education via short message service of Mobile Phone on metabolic control of Patients with Type 2 Diabetes Mellitus in Karaj-Iran. The Horizon of Medical Sciences. 2014; 19(4): 224-34.

13) Mullany BC. Barriers to and attitudes towards promoting husbands' involvement in maternal health in Katmandu, Nepal. Soc Sci Med. 2006; 62(11): 2798-809. doi: 10.1016/j.socscimed.2005.11.013. PMID: 16376007.

14) Ferrer-Roca O, Cardenas A, Diaz-Cardama A, Pulido P. Mobile phone text messaging in the management of diabetes. J Telemed Telecare. 2004; 10(5): 282-5. doi: 10.1258/1357633042026341. PMID: 15494086. 
15) Sacco WP, Morrison AD, Malone JI. A brief, regular, proactive telephone "coaching" intervention for diabetes: rationale, description, and preliminary results. Journal of diabetes and its complications. 2004; 18(2): 113-8. doi: 10.1016/S1056-8727(02)00254-4.

16) Pena V, Watson AJ, Kvedar JC, Grant RW. Mobile phone technology for children with type 1 and type 2 diabetes: a parent survey. Journal of diabetes science and technology. 2009; 3(6): 1481-9. doi: 10.1177/193229680900300630. PMID: 20144404, PMCID: PMC2787050.

17) Zakerimoghadam M, Bassampour S, Rjab A, Faghihzadeh S, Nesari M. Effect of nurse-led telephone follow ups (tele-nursing) on diet adherence among type 2 diabetic patients. Hayat. 2008; 14(2): 63-71.

18) Sadeghi T, Shahabinezhad M, Derakhshan R, Balaei P. Efect Of Nurse-Led Telephone Follow Up (Telenursing) On Hbalc Among Diabetic Patients. Journal of Rafsanjan University of Medical Sciences and Health Services, 2010,3 (36); 175 -184.

19) Black JM, Hawks JH. Medical-surgical nursing. Saunders/Elsevier; 2009.

20) Parizad N, Hemmati M, Khalkhali H. Promoting self-care in patients with type 2 diabetes: tele-education. Hakim Health Sys Res. 2013; 16(3): 220-7.

21) Dehdari T SzD, Zamani Alavjeh F. Communication and Message in Health. 1st Ed. Tehran: Tavangaran Publisher; 2013:12-47.

22) Holmström IM, Rosenqvist U. Misunderstandings about illness and treatment among patients with type 2 diabetes. J Adv Nurs. 2005; 49(2): 146-54. doi: 10.1111/j.1365-2648.2004.03274.x. PMID: 15641947.

23) Ghazanfari Z, Ghofranipour F, Tavafian S, Ahmadi F, Rajab A. Lifestyle education and diabetes mellitus type 2: a non-randomized control trial. Iranian Journal of Public Health. 2007; 36(2): 68-72.

24) Tankova T, Dakovska G, Koev D. Education of diabetic patients - a one year experience. Patient education and counseling. 2001; 43(2): 139-45. doi: 10.1016/S0738-3991(00)00159-2.

25) Parizad N, Hemmati Maslakpak M, Khalkhali HR. The effect of tele-education by telephone and short message service on laboratory parameters in patients with type 2 diabetes. J Ardabil Univ Med Sci. 2014; 14(1): 7-17.

26) Nesari M, Zakerimoghadam M, Rajab A, Bassampour S, Faghihzadeh S. Effect of telephone follow - up on adherence to a diabetes therapeutic regimen. Jpn J Nurs Sci. 2010; 7(2): 121-8. doi: 10.1111/j.17427924.2010.00146.x. PMID: 21092015.

27) Hajiagha A, Nourozi S, Yekaninejad M, Mansouri A, Chaibakhsh S. Effect of message framing on improving oral health behaviors in students in Qazvin, Iran. Journal of Isfahan Dental School. 2013; 8(6): 512-21.

28) Gharaati F, Aghamolaei T, Hassani L, Mohamadi R, Mohsseni S. The effect of educational intervention using mobile phone on self-care behaviors in patients with thalassemia major. Journal of Preventive Medicine. 2016; 3(2): 58-72.

29) Absavaran M, Niknami S, Zareban I. Effect of training through lecture and mobile phone on Breast SelfExamination among nurses of Zabol Hospitals. 2015; 14(3): 363-73.

30) Baker DW, Dewalt DA, Schillinger D, Hawk V, Ruo B, Bibbins-Domingo K, et al. The effect of progressive, reinforcing telephone education and counseling versus brief educational intervention on knowledge, self-care behaviors and heart failure symptoms. Journal of cardiac failure. 2011; 17(10): 78996. doi: 10.1016/j.cardfail.2011.06.374. PMID: 21962415, PMCID: PMC3185245.

31) Goodarzi M, Javadi Bora MA, Farajollahi M. Impact of education via mobile phone on knowledge, attitude, practice and $\mathrm{HbA} 1 \mathrm{C}$ of patients with type 2 diabetes mellitus in Karaj-Iran. Interdisciplinary Journal of Virtual Learning in Medical Sciences. 2015; 6(3): 8-19.

32) Baghiani Moghadam M, Taheri G, Fallah Zadeh H, Parsa M. The effect of instructional designed SMS based on Health Belief Model (HBM) on adoption of self-care behavior of patients with type II diabetes. Modern Care Journal. 2014; 11(1): 10-8.

33) Basiri G, Bagheri M, Fayazi S, Piam HF. Comparison of Effect of Two Methods of Face-to-Face Education and Distance Education (via Short Message Service) on Amount of Following Remedial Diet in Patients Suffering From Hypertension. Jundishapur Journal of Chronic Disease Care. 2016; 5(3): e310960. doi: 10.17795/jjcdc-31096.

34) Fatehi F, Malekzadeh G, Akhavi M, Rashidi M, Afkhami Am. The effect of short message service on knowledge of patients with diabetes in Yazd, Iran. Iranian Journal of Diabetes and Obesity. 2010; 2(1): 2731. 